Original Article

\title{
Evaluation of Short-Term Outcomes and the Learning Curve Wherein a Thoracic Resident Doctor Performed Video-Assisted Thoracoscopic Anatomical Lung Resection for Lung Cancer
}

\author{
Tomohiro Fujita, ${ }^{1,2}$ Shigeyuki Morino, ${ }^{1}$ and Akihiro Nakamura ${ }^{1}$
}

\begin{abstract}
Purpose: The surgical approach for anatomical lung resection includes open thoracotomy, video-assisted thoracoscopic surgery, and robot-assisted thoracoscopic surgery. We evaluated the short-term outcomes and the learning curve wherein a thoracic resident doctor consecutively performed video-assisted thoracoscopic anatomical lung resection for lung cancer.

Methods: We retrospectively reviewed 91 cases of consecutive video-assisted thoracoscopic anatomical lung resections for lung cancer performed by a thoracic resident doctor between November 2017 and March 2020. The thoracic resident doctor had no previous experience performing video-assisted thoracoscopic or open anatomical lung resection.

Results: Lobectomy was performed in 80 cases. Simple segmentectomy was performed in 11 cases. No cases required intraoperative conversion to open thoracotomy. The median operative time and blood loss were $148 \mathrm{~min}$ and $10 \mathrm{ml}$, respectively. There were no serious postoperative complications or deaths 30 days after surgery. The learning curve was examined using the cumulative sum method with operative time as a factor, and it took 21 cases to attain experience.

Conclusion: Our resident doctor safely performed video-assisted thoracoscopic anatomical lung resections and it took 21 cases to stabilize the surgical technique. The surgical technique was possibly stabilized earlier than previously reported, although this was a study of a single resident doctor.
\end{abstract}

Keywords: thoracic resident doctor, learning curve, lung cancer, video-assisted thoracoscopic anatomical lung resection

\footnotetext{
${ }^{1}$ Department of Thoracic Surgery, Sasebo City General Hospital, Sasebo, Nagasaki, Japan

${ }^{2}$ Department of Thoracic Surgery, Aomori Prefectural Central Hospital, Aomori, Aomori, Japan
}

Received: September 22, 2021; Accepted: January 11, 2022 Corresponding author: Tomohiro Fujita, Aomori Prefectural Central Hospital, 2-1-1, Tsukurimichi, Aomori, Aomori 030-8553, Japan Email: tfujita@med.pref.aomori.jp

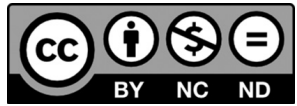

This work is licensed under a Creative Commons Attribution-NonCommercialNoDerivatives International License.

(C)2022 The Editorial Committee of Annals of Thoracic and Cardiovascular Surgery

\section{Introduction}

Currently, surgical approaches for anatomical lung resection for lung cancer include standard open thoracotomy, video-assisted thoracoscopic surgery (VATS), and robot-assisted thoracoscopic surgery (RATS). Among these methods, video-assisted thoracoscopic anatomical lung resection has been reported in many studies, and its safety and usefulness have been proven. ${ }^{1-5)}$ Minimally invasive approaches such as VATS are recommended for early stage lung cancer according to the American 
Fujita T, et al.

College of Chest Physicians (ACCP). ${ }^{6}$ VATS is very important in thoracic surgery; hence, it is a technique that must be mastered even by thoracic resident surgeons. We perform video-assisted thoracoscopic lobectomy or segmentectomy for lung cancer. In this study, we evaluated the short-term surgical outcomes and the learning curve of consecutive anatomical lung resections performed by a thoracic resident doctor who had never performed anatomical lung resection.

\section{Patients and Methods}

This study was conducted on obtaining informed consent from the patients for using the medical records.

The thoracic resident doctor was a fourth-year resident and had performed 10 cases of VATS bullectomy and partial lung resections until April 2017. He performed 231 thoracic surgeries at our department between April 2017 and March 2020. We retrospectively reviewed 91 cases of consecutive video-assisted thoracoscopic anatomical lung resection for lung cancer performed by the thoracic resident doctor from November 2017, the date when he performed his first video-assisted thoracoscopic lung lobectomy, to March 2020. The thoracic resident doctor practiced suturing, ligation, and dissection in the dry lab before the first surgery. Moreover, he trained to fold origami birds via VATS. Furthermore, he performed lobectomy once in the animal wet lab. The study excluded several patients who underwent preoperative radiochemotherapy, those in whom the main operations were performed by the supervising surgeon, and those with a history of thoracic surgery on the operative side. Diagnosis and treatment for lung cancer were based on the ACCP guidelines. ${ }^{6}$ In all cases, the decision as to whether lobectomy or segmentectomy is feasible was made by calculating the predicted percentage of forced expiratory volume in $1.0 \mathrm{~s}\left(\% \mathrm{FEV}_{1.0}\right)$ and the percentage of diffusing capacity for carbon monoxide (\%DLCO) as covariates after pulmonary resection. A predicted $\% \mathrm{FEV}_{1.0}$ and $\% \mathrm{DLCO}$ after lung resection of $\geq 40 \%$ served as an indication.

We obtained information on patient characteristics and operative findings from the medical records. Postoperative complications were classified using the ClavienDindo classification. ${ }^{7)}$ The Mann-Whitney U test was used to compare non-normally distributed continuous variables. The cumulative sum (CUSUM) method was used to evaluate the learning curve. ${ }^{8)} \mathrm{A}$ two-tailed p-value of $<0.05$ was considered statistically significant. Statistical analyses were performed using the EZR program. ${ }^{9)}$

\section{Surgical technique}

The patient was placed in the lateral decubitus position after general anesthesia and one-lung ventilation. In all cases, the surgeon stood on the right side of the patient while performing the surgery.

Video-assisted thoracoscopic anatomical lung resection was performed through a mini-thoracotomy. A 6-cm axillary mini-thoracotomy was performed, and two 12-mm ports for the VATS were inserted, following which the surgery was performed with both monitored and direct vision. The interlobar plasty was performed first. The pulmonary artery and vein were dissected in this order. Finally, the bronchus was dissected. Mediastinal lymph node dissection (ND2a-1) was performed after lobectomy in all patients. The ports were inserted when the angle of insertion of the stapler did not match the angle of the pulmonary artery and vein or bronchial dissection.

Three doctors were involved in the surgery. The primary surgeon was a thoracic resident doctor, and the first assistant and scopist were supervising surgeons who were board certified in thoracic surgery. The thoracic resident doctor performed tissue separation, lung suturing, and dissection of blood vessels and bronchi using the stapler or vessel sealing device. The supervisor developed the field of view during the surgery and advised on surgical techniques.

\section{Postoperative management}

None of the patients required postoperative ventilator management, and they were admitted to the intensive care unit. Rehabilitation was initiated on postoperative day 1. Thoracic drains were removed on the day after surgery if there were no problems with drainage volume or properties and if there were no pulmonary air leaks. The patients were discharged on postoperative day 5 if there were no abnormalities in the general condition.

\section{Results}

The median age of the patients was 69 years; 51 patients were males and 40 were females (Table 1). Eight-nine patients had primary lung cancer, and two patients had metastatic lung tumors. Lobectomy was performed in 80 patients, with right upper lobectomy being the most common (33 patients). Eleven patients underwent segmentectomy, all of whom underwent simple segmentectomy of the superior segment or left upper segment. No case required intraoperative conversion to open thoracotomy. The median operative time and blood 
Table 1 Characteritics and perioperative factors of patients

\begin{tabular}{lc}
\hline & All cases (91 cases) \\
\hline Age (median) (range) & $69.0(39.0-86.0)$ \\
Sex & \\
Male & $51(56.0 \%)$ \\
Female & $40(44.0 \%)$ \\
Diagnosis & \\
$\quad$ Primary lung cancer & $89(97.8 \%)$ \\
Metastatic lung cancer & $2(2.2 \%)$ \\
Clinical stage & \\
$\leq$ IA3 & $61(67.0 \%)$ \\
IB-IIIA & $28(30.8 \%)$ \\
Operative method & \\
Right upper lobectomy & $33(36.3 \%)$ \\
Right middle lobectomy & $10(11.0 \%)$ \\
Right lower lobectomy & $16(17.6 \%)$ \\
Left upper lobectomy & $9(9.9 \%)$ \\
Left lower lobectomy & $12(13.2 \%)$ \\
Simple segmentectomy & $11(12.1 \%)$ \\
Operative time (median) (range) (min) & $148.0(92.0-274.0)$ \\
Blood loss (median) (range) (ml) & $10.0(2.0-92.0)$ \\
Complication of CD grade $\geq$ III & 0 \\
Convert to open thoracotomy & 0 \\
\hline CD &
\end{tabular}

CD grade: Clavien-Dindo grade

loss were $148 \mathrm{~min}$ and $10 \mathrm{ml}$, respectively. There were no serious complications of grade III or higher based on the Clavien-Dindo classification, ${ }^{7)}$ and there were no deaths 30 days after surgery. The operative time tended to be longer in the initial cases (Fig. 1). The amount of blood loss was similar in all cases at all time points; however, in many cases, where the amount of blood loss was $>50 \mathrm{ml}$, adhesions between the lung and the chest wall or incomplete fissures were observed. The operative time and blood loss were compared according to the type of anatomical lung resection, technique for lobectomy, and clinical stage; however, there was no statistically significant difference between any of them (Table 2). The learning curve for the operative time was examined, and it took 21 cases before the operative time stabilized (Fig. 2). The operative time was significantly shorter in Phase 3 when patient characteristics and perioperative factors were compared in each phase (Table 3).

\section{Discussion}

The ACCP guidelines recommend VATS as the surgical approach for anatomical lung resection for non-small cell lung cancer.6) A total of 4685 cases of segmentectomy and 31584 cases of lobectomy were performed for primary lung cancer in Japan in 2017, and the proportion of cases performed by VATS was reported to be $78.9 \%$ and $69.6 \%$, respectively. ${ }^{10)}$ Hence, VATS for anatomical lung resection is an essential technique for thoracic resident surgeons in Japan to learn; however, it is extremely challenging in terms of delicate and complicated surgical techniques and serious intraoperative complications. It takes 26-60 cases to acquire satisfactory surgical skills for video-assisted thoracoscopic lobectomy. ${ }^{11-13)}$ Furthermore, it is recommended that there should be exposure to several cases in a short period, if possible. However, new

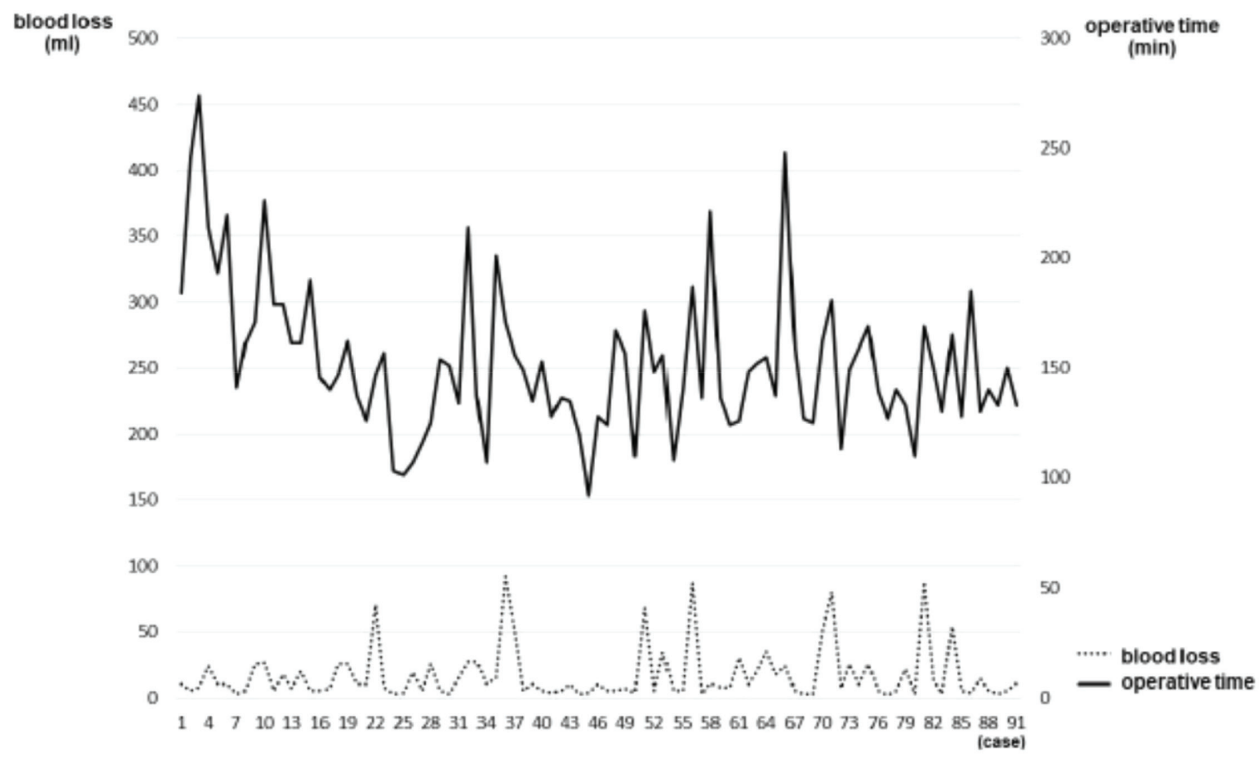

Fig. 1 Operative time and blood loss wherein a thoracic resident doctor performed video-assisted thoracoscopic anatomical lung resection. Figure 1 shows the operative time and blood loss for all cases. The operative time and blood loss are shown as a solid line and a dotted line, respectively. 
Fujita T, et al.

Table 2 Comparison of surgical time and blood loss in each factors

\begin{tabular}{lccc}
\hline & Lobectomy & Segmentectomy & p-Value \\
\hline Operative time (min) (median) (range) & $148.0(92.0-274.0)$ & $140.0(126.0-248.0)$ & 0.951 \\
Blood loss (ml) (median) (range) & $9.0(3.0-92.0)$ & $10.0(2.0-25.0)$ & 0.425 \\
\hline & Left upper lobectomy & Other lobe lobectomy & p-Value \\
\hline Operative time (min) (median) (range) & $137.0(133.0-176.0)$ & $149.0(92.0-274.0)$ & 0.433 \\
Blood loss (ml) (median) (range) & $8.0(3.0-68.0)$ & $10.0(3.0-92.0)$ & 0.927 \\
\hline & cStage $\leq \mathbf{I A 3}$ & cStage IB-IIIA & p-Value \\
\hline Operative time (min) (median) (range) & $149.0(101.0-274.0)$ & $140.0(92.0-214.0)$ & 0.356 \\
Blood loss (ml) (median) (range) & $10.0(2.0-92.0)$ & $5.0(3.0-80.0)$ & 0.107 \\
\hline
\end{tabular}

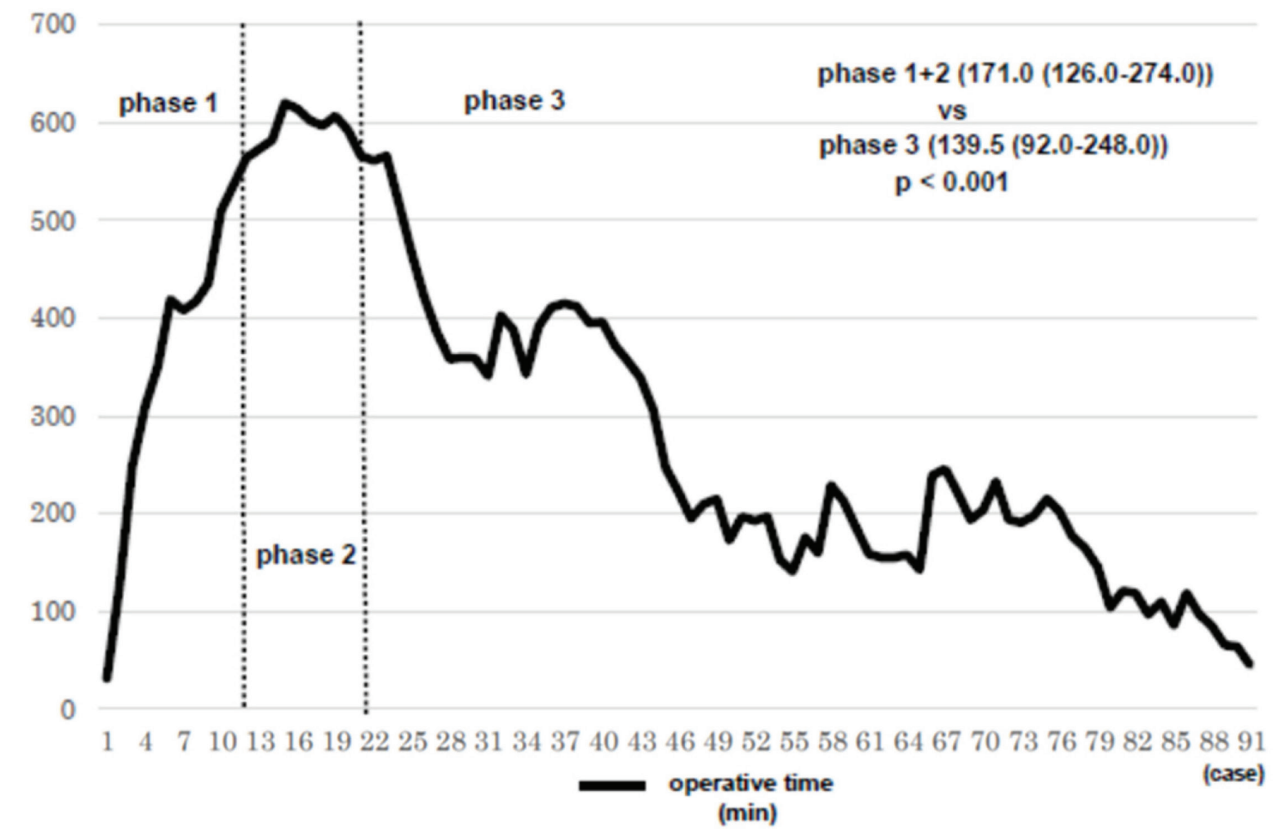

Fig. 2 Learning curve wherein a resident doctor performed video-assisted thoracoscopic anatomical lung resection. Figure 2 shows the learning curve using the CUSUM method. The 12th case was in Phase 1, the 13th case to the 21st case were in Phase 2, and the 22nd and subsequent cases were in Phase 3. CUSUM: cumulative sum

approaches such as RATS ${ }^{14-16)}$ and single- port thoracoscopic surgery ${ }^{17,18)}$ have emerged in Japan, and early stage lung cancer with complete fissures is often eligible for these approaches. Therefore, there are few opportunities for thoracic resident doctors to experience videoassisted thoracoscopic anatomical lung resection, and many institutions are facing challenges in educating thoracic resident doctors. As a solution to this problem, it has been reported that the creation of video-assisted thoracoscopic lobectomy simulators and training programs, the use of dry or wet labs, and the introduction of virtual-reality technology into these programs are useful in educating thoracic resident doctors. ${ }^{19-23)}$ In this study, the thoracic resident doctor trained in dry and wet labs before the first surgery. He trained in suturing using models and folding birds with origami paper in the dry lab. The wet lab was performed once, at which time lobectomy was performed. This process was useful.

There are several possible evaluation factors for surgical techniques; however, in the present study, we used operative time and blood loss to evaluate the stability of the technique. The amount of blood loss was difficult to evaluate because the amount of blood loss was small in the initial cases and there was no fixed trend. The CUSUM method ${ }^{8)}$ was used to evaluate the learning curve for operative time, and the 12th case was in Phase 1, the 13th to the 21st cases were in Phase 2, and the 22nd and subsequent cases were in Phase 3. The number of 
Table 3 Characteristics and perioperative factors of patients in each phase

\begin{tabular}{|c|c|c|c|c|}
\hline & Phase 1 (12 cases) & Phase 2 ( 9 cases $)$ & Phase 3 ( 70 cases) & p-Value \\
\hline Age (median) (range) & $69.0(60.0-86.0)$ & $68.0(39.0-83.0)$ & $69.0(41.0-86.0)$ & 0.899 \\
\hline \multicolumn{5}{|l|}{ Sex } \\
\hline Male & $6(50.0 \%)$ & $5(55.6 \%)$ & $40(57.1 \%)$ & \multirow[t]{2}{*}{0.899} \\
\hline Female & $6(50.0 \%)$ & $4(44.4 \%)$ & $30(42.9 \%)$ & \\
\hline \multicolumn{5}{|l|}{ Diagnosis } \\
\hline Primary lung cancer & $12(100.0 \%)$ & $9(100.0 \%)$ & $68(97.1 \%)$ & \multirow[t]{2}{*}{0.736} \\
\hline Metastatic lung cancer & 0 & 0 & $2(2.9 \%)$ & \\
\hline \multicolumn{5}{|l|}{ Clinical stage } \\
\hline$\leq \mathrm{IA} 3$ & $9(75.0 \%)$ & $7(77.8 \%)$ & $45(66.2 \%)$ & \multirow[t]{2}{*}{0.682} \\
\hline IB-IIIA & $3(25.0 \%)$ & $2(22.2 \%)$ & $23(33.8 \%)$ & \\
\hline \multicolumn{5}{|l|}{ Type of anatomical lung resection } \\
\hline Lobectomy & $11(91.7 \%)$ & $7(77.8 \%)$ & $62(88.6 \%)$ & \multirow[t]{2}{*}{0.589} \\
\hline Simple segmentectomy & $1(8.3 \%)$ & $2(22.2 \%)$ & $8(11.4 \%)$ & \\
\hline \multicolumn{5}{|l|}{ Operative method } \\
\hline Left upper lobectomy & 0 & 0 & $9(14.5 \%)$ & \multirow[t]{2}{*}{0.229} \\
\hline Other lobe lobectomy & $11(100.0 \%)$ & $7(100.0 \%)$ & $53(85.5 \%)$ & \\
\hline Operative time (min) (median) (range) & $188.5(141.0-274.0)$ & $147.0(126.0-190.0)$ & $139.5(92.0-248.0)$ & $<0.001$ \\
\hline Blood loss (ml) (median) (range) & $10.0(3.0-26.0)$ & $10.0(5.0-25.0)$ & $8.0(2.0-92.0)$ & 0.872 \\
\hline
\end{tabular}

cases up to Phase 2 was considered to be the number of cases required for proficiency. In this study, 21 cases were required. The results of this study are excellent and are comparable to those of previous reports. ${ }^{11-13)} \mathrm{We}$ believe that standardized procedures for dissection of the pulmonary artery or vein and dissection of mediastinal lymph nodes and the surgical process contributed to smoother learning. Furthermore, it is important to standardize the procedures so that they can be performed without confusion, even when the resected lung lobe or operative method differs. On the other hand, in the case of incomplete fissures or adhesions, the operative time was longer and the amount of blood loss increased at any stage of the operation; thus, more experience is needed in these cases.

The results of this short-term surgical outcome were good, as there were no serious complications in all patients and no deaths occurred 30 days after surgery. We perform VATS through mini-thoracotomy, and we believe that the combined use of monitored and direct vision allowed even the thoracic resident doctor to grasp the anatomy more accurately, thereby allowing the doctor to perform the surgery safely. There have been few previous reports on the learning curve of VATS anatomical lung resection performed by resident thoracic doctors. We performed this study on a surgeon with no prior experience in anatomical lung resection. In this study, we were able to prove that the surgery was safe and smooth even for a resident thoracic doctor. The results of this study are relatively new findings, and we believe that they will provide a useful message for future education of VATS anatomical lung resection.

\section{Limitations}

There were several limitations in this study. First, this study was an evaluation of one thoracic resident doctor and retrospectively conducted in a single institution. In the future, multi-center trial with many thoracic resident doctors is required to give more confidence to the results of this study. Second, there was bias in patient selection. Most of the cases wherein a thoracic resident doctor performed were early stage lung cancer with no invasion to surrounding organs or lymph node metastasis.

\section{Conclusion}

Video-assisted thoracoscopic anatomical lung resection was safely performed by a resident doctor, and it took 21 cases before the technique was stabilized.

\section{Acknowledgments}

The authors thank all members of the Department of Thoracic Surgery and General Surgery, Sasebo City General Medical Center.

\section{Disclosure Statement}

The authors declare no conflicts of interest. 
Fujita T, et al.

\section{References}

1) Cai YX, Fu XN, Xu QZ, et al. Thoracoscopic lobectomy versus open lobectomy in stage I non-small cell lung cancer: a meta-analysis. PLoS One 2013; 8: e82366.

2) Cao C, Zhu ZH, Yan TD, et al. Video-assisted thoracic surgery versus open thoracotomy for non-small-cell lung cancer: a propensity score analysis based on a multi-institutional registry. Eur J Cardiothorac Surg 2013; 44: 849-54.

3) Murakawa $\mathrm{T}$, Ichinose J, Hino H, et al. Long-term outcomes of open and video-assisted thoracoscopic lung lobectomy for the treatment of early stage non-small cell lung cancer are similar: a propensity-matched study. World J Surg 2015; 39: 1084-91.

4) Shigemura N, Akashi A, Funaki S, et al. Long-term outcomes after a variety of video-assisted thoracoscopic lobectomy approaches for clinical stage IA lung cancer: a multi-institutional study. J Thorac Cardiovasc Surg 2006; 132: 507-12.

5) Yan TD, Black D, Bannon PG, et al. Systematic review and meta-analysis of randomized and nonrandomized trials on safety and efficacy of video-assisted thoracic surgery lobectomy for early-stage non-small-cell lung cancer. J Clin Oncol 2009; 27: 2553-62.

6) Howington JA, Blum MG, Chang AC, et al. Treatment of stage I and II non-small cell lung cancer: diagnosis and management of lung cancer, 3rd ed: American College of Chest Physicians evidence-based clinical practice guidelines. Chest 2013; 143: e278S-313S.

7) Dindo D, Demartines N, Clavien PA. Classification of surgical complications: a new proposal with evaluation in a cohort of 6336 patients and results of a survey. Ann Surg 2004; 240: 205-13.

8) Bokhari MB, Patel CB, Ramos-Valadez DI, et al. Learning curve for robotic-assisted laparoscopic colorectal surgery. Surg Endosc 2011; 25: 855-60.

9) Kanda Y. Investigation of the freely available easy-touse software 'EZR' for medical statistics. Bone Marrow Transplant 2013; 48: 452-8.

10) Shimizu H, Okada M, Tangoku A, et al. Thoracic and cardiovascular surgeries in Japan during 2017: annual report by the Japanese Association for Thoracic Surgery. Gen Thorac Cardiovasc Surg 2020; 68: 414-49.
11) McKenna RJ Jr. Complications and learning curves for video-assisted thoracic surgery lobectomy. Thorac Surg Clin 2008; 18: 275-80.

12) Zhao H, Bu L, Yang F, et al. Video-assisted thoracoscopic surgery lobectomy for lung cancer: the learning curve. World J Surg 2010; 34: 2368-72.

13) Yao F, Wang J, Yao J, et al. Video-assisted thoracic surgical lobectomy for lung cancer: description of a learning curve. J Laparoendosc Adv Surg Tech A 2017; 27: 696-703.

14) Emmert A, Straube C, Buentzel J, et al. Robotic versus thoracoscopic lung resection: a systematic review and meta-analysis. Medicine (Baltimore) 2017; 96: e7633.

15) Zhang L, Gao S. Robot-assisted thoracic surgery versus open thoracic surgery for lung cancer: a system review and meta-analysis. Int J Clin Exp Med 2015; 8: $17804-10$.

16) Ye $X, X i e ~ L$, Chen G, et al. Robotic thoracic surgery versus video-assisted thoracic surgery for lung cancer: a meta-analysis. Interact Cardiovasc Thorac Surg 2015; 21: 409-14.

17) Yao J, Chang Z, Zhu L, et al. Uniportal versus multiportal thoracoscopic lobectomy: ergonomic evaluation and perioperative outcomes from a randomized and controlled trial. Medicine (Baltimore) 2020; 99: e22719.

18) Gonzalez-Rivas D, Paradela M, Fernandez R, et al. Uniportal video-assisted thoracoscopic lobectomy: two years of experience. Ann Thorac Surg 2013; 95: 426-32.

19) Sezen CB, Kocaturk CI. Videothoracoscopic lobectomy training in non-small cell lung cancer. Turk Gogus Kalp Damar Cerrahisi Derg 2019; 27: 199_ 205.

20) Divisi D, Barone M, Zaccagna G, et al. Video-assisted thoracoscopic surgery lobectomy learning curve: what program should be offered in a residency course? J Vis Surg 2017; 3: 143.

21) Bedetti B, Schnorr P, Schmidt J, et al. The role of wet lab in thoracic surgery. J Vis Surg 2017; 3: 61.

22) Petersen RH, Hansen HJ. Learning curve associated with VATS lobectomy. Ann Cardiothorac Surg 2012; 1: 47-50.

23) Petersen RH, Hansen HJ. Learning thoracoscopic lobectomy. Eur J Cardiothorac Surg 2010; 37: 516-20. 